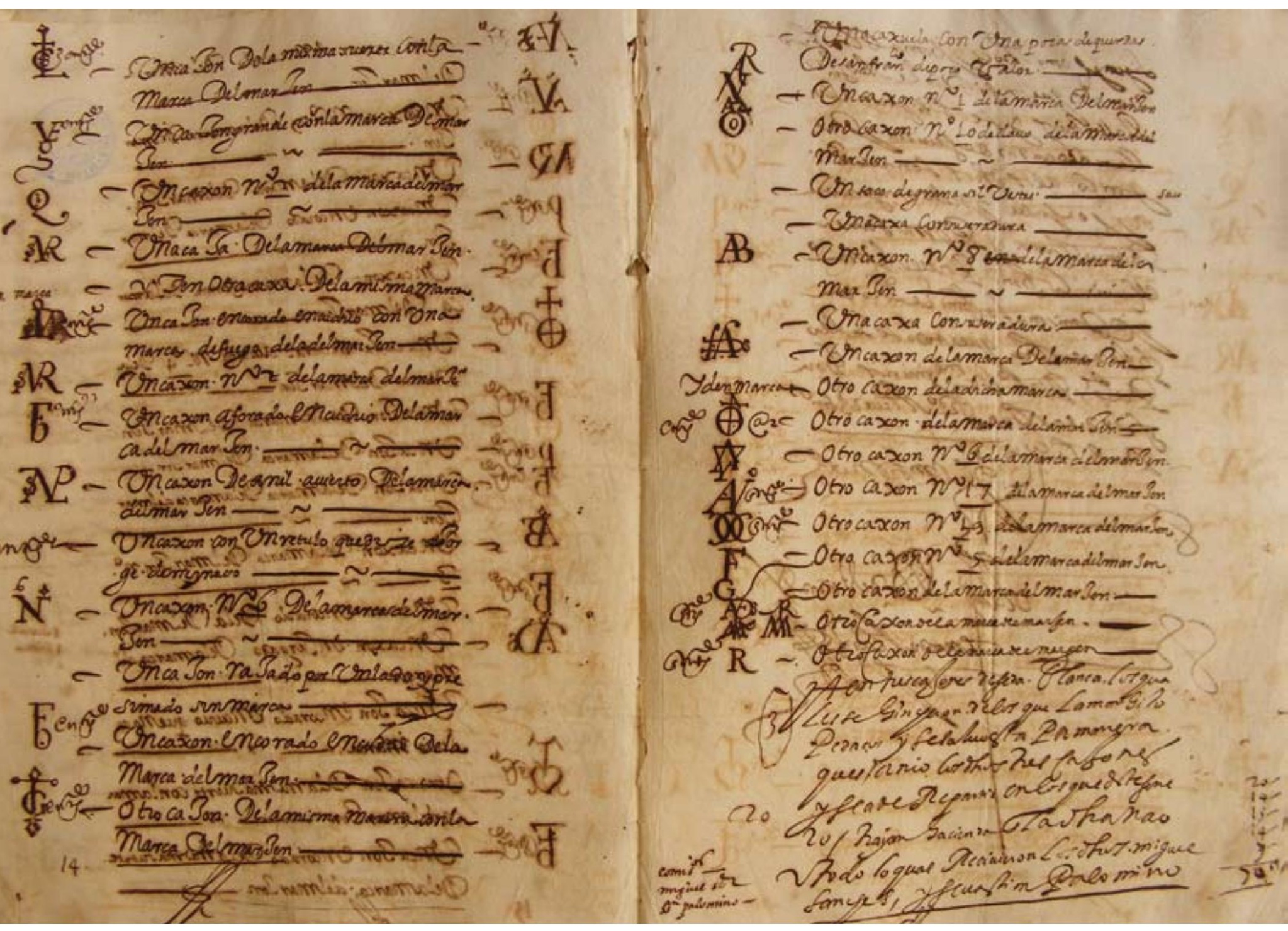

1. Expediente donde se relacionan los propietarios y marcas de identificación del cargamento del navío San Esteban, naufragado en 1612. Foto: A. Valiente, CAS-IAPH. Fuente: Archivo Histórico de la Cámara de Comercio de Sevilla, Leg. 520 


\section{El conocimiento del patrimonio arqueológico subacuático desde la perspectiva de las fuentes documentales}

Carlos Alonso Villalobos, Lourdes Márquez Carmona, Antonio Valiente Romero, David Benítez López, Área de Documentación del Centro de Arqueología Subacuática (CAS), IAPH

\section{Resumen}

Desde su creación, el Centro de Arqueología Subacuática (CAS) del Instituto Andaluz del Patrimonio Histórico desarrolla un amplio proyecto de investigación sobre fuentes documentales relativas al patrimonio cultural sumergido de Andalucia. La finalidad es identificar instituciones o particulares que custodian fondos documentales de esta naturaleza, caracterizando las series que las componen según su calidad como fuentes de información, investigándolas y sistematizando la información obtenida en el Sistema de Gestión ideado y desarrollado para tal fin (SIGNauta). Con este proyecto se pretende, además de mejorar el conocimiento acerca de este patrimonio emergente, poner en servicio una herramienta de información adaptada a las necesidades de su tutela.

\section{Palabras clave}

Archivos / Arqueología subacuática / Cádiz (Bahía de) / Centro de Arqueología Subacuática / Documentación / Fuentes documentales / Golfo de Cádiz / Guadalquivir (Rio) / Instituto Andaluz del Patrimonio Histórico / Investigación / Naufragios / Patrimonio arqueológico subacuático / Sistemas de información geográficos 


\section{INTRODUCCIÓN}

Para explicar la importancia que la investigación arqueológica de un naufragio tiene como fuente de información histórica es recurrente afirmar que un pecio es una "cápsula del tiempo". Todo lo que transportaba el barco (carga, tripulación, pasajeros, artillería, etc.), además de su propia estructura, conforma un conjunto arqueológico coetáneo que, por causas diversas, acabó en el fondo de las aguas. Su estudio permite datar con gran exactitud la embarcación y los materiales asociados, pero además facilita información sobre diversas temáticas como el comercio marítimo de la época, la construcción naval, la vida a bordo y, quizás, las causas por las que la embarcación nunca llegó a su puerto de destino. A partir del siglo XI, el análisis arqueológico de los pecios cuenta con una gran aliada en la labor de recuperar la memoria de nuestro pasado: la documentación histórica custodiada en los archivos, más precisa y abundante conforme nos referimos a momentos más recientes de la historia.

Si bien es casi imposible que la excavación de pecios de época clásica o medieval alcance conclusiones acerca de, por ejemplo, el nombre de la embarcación, los propietarios de la carga, el piloto, etc., el estudio de la documentación histórica conservada en los archivos permite identificar no sólo este tipo de aspectos, sino además la identidad de la tripulación o el pasaje; el inventario de mercancias transportadas (con su origen y destino, propietario, marcas de propiedad, precios, etc.) (imagen 1); referencias a la artillería (lugar de fundición, características, coste de las piezas, etc.); detalles técnicos de la embarcación (historia del barco, datos de construcción, reparaciones, planos, etc.); tipos de seguros maritimos al uso, etc. Además, más allá de la propia investigación arqueológica, la documentación histórica es de utilidad para otros fines. Frente al reducido número de zonas arqueológicas subacuáticas conocidas, como consecuencia de la juventud de esta disciplina científica, la documentación histórica es útil para referenciar miles de naufragios históricos, un amplio elenco de yacimientos potenciales que deben ser tutelados desde la administración competente. Su estudio se convierte asi en una necesidad para poder definir estrategias, no sólo de investigación, sino también de protección y difusión de los valores de estos bienes culturales. Es el caso de la reciente declaración de Zonas de Servidumbre Arqueológica del litoral andaluz, apoyada en buena parte en los centenares de naufragios documentados en el proceso de investigación llevado a cabo desde el Área de Documentación del CAS.

\section{UN PATRIMONIO POR CONOCER}

Desde la antigüedad existen referencias sobre la localización de restos de embarcaciones perdidas y la utilización de complejos sistemas para su rescate, sin embargo el origen y desarrollo de la arqueología subacuática como disciplina científica no puede remontarse más allá de mediados del siglo XX.
El progreso en diversos ámbitos de la ciencia, especialmente tras la Segunda Guerra Mundial, permitió el perfeccionamiento del método arqueológico, favoreciendo tanto la localización de nuevos yacimientos, como el conocimiento más profundo de los ya identificados. El desarrollo de la sedimentología, la dendrocronología y las técnicas de datación con carbono- $14\left({ }^{14} \mathrm{C}\right)$ abrieron nuevas vías de estudio para conocer, de manera relativa o absoluta, la edad de los niveles arqueológicos y los elementos materiales asociados a los mismos. Junto a ello, la aplicación de la fotografía aérea, la introducción de la palinología, o el uso del sistema cartesiano como base de referencia para la excavación posibilitaron mejorar considerablemente las técnicas de localización, excavación y caracterización de los antiguos asentamientos.

En el ámbito que nos ocupa, la invención de las aletas de buceo (1935), el tubo de respiración (1938), las gafas (1938) y, principalmente, el regulador (1943), ideado por Jacques-Yves Cousteau y Emile Gagnan para fines originariamente militares, posibilitaron el desarrollo del buceo autónomo y, con ello, el inicio de la investigación científica subacuática en diferentes campos, entre ellos, el de la arqueología.

La rápida expansión del buceo autónomo al ámbito deportivo favoreció la localización y recuperación de parte de la carga de muchos naufragios, principalmente en aguas del Mediterráneo, pero no será hasta principio de los 70 cuando, gracias a la adaptación de las técnicas de investigación y registro arqueológico (prospección, posicionamiento, documentación gráfica, excavación, etc.) al medio subacuático, se posibilite la excavación científica de un pecio.

Ya desde los años 50 se tienen noticias sobre la recuperación en España de ánforas y otros elementos por buceadores deportivos, pero no será hasta los años 80 cuando se inicie el primer proyecto científico encaminado a conocer la realidad de nuestro patrimonio arqueológico subacuático: el Plan Nacional de Documentación del Litoral Español, impulsado por el Estado con el fin de iniciar la elaboración de las Cartas Arqueológicas Subacuáticas de nuestro pais. Las primeras acciones realizadas para este Plan permitieron identificar un buen número de yacimientos, si bien la escasez de inversión destinada, el reducido número de profesionales cualificados para afrontar este tipo de estudios, la inexistencia de infraestructura de investigación y la falta de continuidad condicionaron el escaso alcance del mismo.

En la década de los 90 la Consejería de Cultura de la Junta de Andalucía decidió crear un centro especializado desde el que desarrollar proyectos y acciones para la tutela de este patrimonio: el Centro de Arqueología Subacuática, integrado desde entonces como un servicio del Instituto Andaluz del Patrimonio Histórico (GARCIA RIVERA et ál., 1999). Entre las primeras acciones que se le encomendaron estaba la de poner al día la información sobre yacimientos arqueológicos subacuáticos existentes en aguas continentales y maritimas del litoral andaluz y valorar los posibles factores de riesgo para su preservación (ALZAGA GARCíA et ál., 1999). Entre otras conclusiones, el proyecto sirvió para poner de manifiesto la visión 
sesgada que se tenía de este patrimonio, así como la necesidad de abordar por parte del Centro de Arqueología Subacuática una línea de investigación encaminada a mejorar el conocimiento de nuestro patrimonio sumergido: la elaboración de la Carta Arqueológica Subacuática de Andalucía, labor en la que, desde entonces, se viene trabajando como instrumento base para planificar estrategias para la protección, investigación y difusión de estos bienes culturales (GARCIÁ RIVERA; ALZAGA GARCÍA, 2008: 133).

\section{EL PROYECTO DE INVESTIGACIÓN DEL CAS-IAPH SOBRE LAS FUENTES DOCUMENTALES DE INFORMACIÓN}

Como paso previo al desarrollo de los trabajos arqueológicos de prospección y reconocimiento, toda carta arqueológica debe incluir una fase previa de documentación, encaminada a recopilar y sistematizar la información, tanto arqueológica (materiales procedentes de la zona de estudio), como documental (noticias escritas, orales, iconográficas o cartográficas, etc.), acerca de posibles naufragios, estructuras maritimo-fluviales, hallazgos aislados, etc. En este campo ha venido trabajando el Área de Documentación del CAS-IAPH desde el año 1998, desarrollando un amplio proyecto de investigación documental con cuatro objetivos bien definidos:

1. Identificar las fuentes documentales relativas al patrimonio arqueológico subacuático andaluz, analizando su distribución geográfica, y caracterizando las series documentales de mayor interés.

2. Diseñar estrategias para la investigación y explotación de estas fuentes documentales.

3. Sistematizar su información mediante el uso de herramientas de gestión normalizadas en cada uno de sus campos temáticos.

4. Desarrollar proyectos propios de investigación para identificar el patrimonio cultural subacuático andaluz.

\section{Identificar las fuentes documentales y definir su distribución geográfica}

La Real Academia define documento como: "Diploma, carta, relación u otro escrito que ilustra acerca de algún hecho, principalmente de los históricos". A diferencia de los libros, que tienen entidad en sí mismos, con el fin de ser leídos, la función del documento radica en el almacenamiento para ser utilizado como garante de ejecución de ciertas acciones a nivel público o privado. Cumplida esta función, el documento pasa a ser histórico, adquiriendo entidad como fuente de información acerca de hechos del pasado. Es por ello que las fuentes documentales son un elemento básico para el estudio de cualquier proceso o coyuntura de la Historia y, por tanto, de los bienes culturales asociados a ella.

El conjunto de documentos articulado, bien en función a la naturaleza de los órganos productores-receptores, o a su funcionalidad, constituye lo que denominamos el archivo. Etimológicamente, el nombre archivo procede de Archeion ("palacio del magis- trado"), por ser aquí donde se gobernaba y se conservaban los actos del gobierno. Las primeras evidencias sobre su existencia las encontramos en el mundo mesopotámico y en el antiguo Egipto, evolucionando su concepto, a lo largo de la Historia, en paralelo a la propia historia de los pueblos que los generaban.

A partir de la Alta Edad Media, el Estado deja de tener una función preponderante en el control y conservación de la información plasmada en los distintos soportes documentales, que pasa a manos de la Iglesia. Además, los particulares comienzan a mostrar su interés por conservar en buen estado la documentación emanada de sus actividades, como garantía de su preservación en el marco de la consolidación de la fe pública. Nace asi el concepto de documento privado, alimentado tanto por la doctrina diplomática como por la jurídica anterior, caracterizado por regular relaciones sociales y comerciales (principalmente marítimas) entre particulares. Todo ello generó una gran diversificación temática y tipológica de la documentación custodiada en los archivos.

En este marco general, durante la primera fase se pretendia localizar el mayor número de instituciones, organismos o particulares que custodiaran fondos documentales de interés para nuestro proyecto, en relación a su vinculación con funciones de control de comercio marítimo, defensa del litoral o reconocimiento geográfico. Atendiendo al ente productor que generó los fondos documentales, las fuentes de información pueden ser de carácter público y privado.

\section{Fuentes de información públicas}

Son aquellas emanadas de órganos dependientes del Estado en cumplimiento y desarrollo de la normativa vigente, siendo las principales funciones con las que se vinculan las siguientes:

- Fiscales

Derivadas fundamentalmente de los sistemas de exacción aplicados en cada época a las operaciones de transporte de mercancías. Por su importancia y volumen son de destacar los fondos contenidos en el Archivo General de Simancas y el Archivo Histórico Nacional, pero en relación con el patrimonio arqueológico subacuático andaluz y el comercio americano es sin duda el Archivo General de Indias una de las fuentes de primer orden. La documentación que custodia es extensa y diversa, pero destaca la vertiente fiscal, dado que los sistemas de exacción sobre las actividades entre España y América constituyen uno de los ejes fundamentales de la articulación de la Carrera de Indias.

\section{- Judiciales}

Derivadas fundamentalmente de las labores administrativas generadas por la pérdida de embarcaciones (naufragios fraudulentos para el cobro de seguros, incompetencia de los pilotos, etc.). En estos casos las fuentes aportan gran número de detalles sobre el suceso en cuestión, dado que contienen los testimonios de buena parte de la tripulación superviviente. En el caso de la navegación y el comercio 
con las colonias americanas son cruciales los fondos custodiados en el Archivo General de Indias, si bien, fuera de este ámbito, la jurisdicción correspondía a otros tribunales, como por ejemplo las Reales Audiencias o las Chancillerias.

\section{- Militares}

La pérdida de embarcaciones era debida en ocasiones a actos de confrontación militar con escuadras de otros paises o bandas de piratas. Debido a la casuística de la navegación española en la Edad Moderna, el contenido de estas fuentes documentales puede situarse a medio camino entre el carácter público y privado. En muchos casos, embarcaciones civiles eran fletadas para la realización de actividades militares o misiones de estado (como veremos más adelante para el caso de la urca Merchant Royal), a la vez que naves de carácter puramente militar, en muchos casos trasladaban carga de particulares para aumentar la rentabilidad de una expedición (como veremos más adelante para el caso de la Fragata Nuestra Señora de las Mercedes), como solía ocurrir habitualmente con los galeones de la Armada del Mar Océano. En estos casos, a las fuentes documentales mencionadas se unen fondos de carácter propiamente militar, destacando entre ellos las secciones del Consejo de Guerra del Archivo General de Simancas, los fondos del Archivo General Álvaro Bazán (Viso Del Marqués Ciudad Real) o los de las distintas capitanías generales, además de un amplio volumen de documentación dispersa entre las secciones que componen el Archivo Histórico Nacional.

\section{- Control del espacio marítimo}

La vigilancia de los espacios portuarios y zonas costeras sensibles, amenazadas por ataques de piratas o el contrabando, generó una amplia y variada documentación emanada de actividades de vigía, avisos de embarcaciones, siniestros durante la singladura, etc. Estos fondos se encuentran distribuidos entre multitud de archivos, destacando si cabe por su carácter homogéneo la serie constituida por los partes de vigía. Para el caso de la ciudad de Cádiz, fueron ampliamente analizados en el marco del proyecto de documentación del CAS-IAPH, trabajo bastante fructífero en cuanto a los resultados obtenidos. También se agrupan en el marco de esta tipología la serie avisos, opúsculos impresos que comienzan a publicarse en el siglo XVII y constituyen el germen de la prensa (VALIENTE ROMERO; MÁROUEZ CARMONA, 2006: 162-163).

\section{- Fe pública}

Del hecho de dar fe pública de un acto jurídico entre particulares surge la documentación notarial, que cuenta con la peculiaridad de mantener su carácter legal a pesar del paso del tiempo. Su tipología es muy variada, hasta el punto de que, según Bono y Huerta, "un único sistema como unidad plenamente estructurada de hechos documentales forma la gran masa de la documentación notarial" (BONO Y HUERTA, 1992: 73). La diversidad de temas para los que era requerida la labor notarial (compraventas, testamentos y herencias, seguros, etc.) condiciona que, entre la documentación generada, se conserve información acerca de naufragios.
Para afrontar la investigación de estas fuentes con una cierta garantía de éxito para el tipo de patrimonio que nos interesa, es preciso al menos conocer previamente el nombre del barco. Ello se debe a la forma en que los escribanos públicos desarrollaban su labor y al sistema empleado para el almacenaje de la información. En cada localidad podian existir múltiples escribanias públicas. Cada una custodiaba la documentación generada por orden de producción, sin tener en cuenta su tipología o contenido. En algunos casos existen indices de las notarias, pero al ser lamentablemente una práctica poco habitual, la investigación de estos fondos se convierte en una labor muy compleja.

\section{Otras fuentes privadas y colecciones}

Al margen de estas series tipológicas, existen otras de carácter mucho más irregular que, en muchos casos, pueden aportar información de interés de cara al conocimiento del patrimonio arqueológico subacuático. Nos referimos a los archivos privados y las colecciones facticias.

Los archivos privados de interés para el conocimiento del patrimonio arqueológico subacuático se caracterizan por custodiar fondos generados por personas o compañias implicadas de algún modo en el tráfico marítimo, y que, por razones diversas, se han conservado hasta nuestros días. En algunos casos excepcionales son archivos de compañias aún activas, mientras que en otros, tras desaparecer éstas, la documentación se ha dispersado y preservado bien en otras instituciones o en manos de coleccionistas.

También fruto del coleccionismo, aunque en el marco de la preservación del patrimonio documental, es la creación de series facticias de carácter temático llevadas a cabo últimamente por algunos archivos, destacando los casos del Archivo General de Indias y Archivo General de Andalucia. Dada la gran especificidad de este tipo de fondos documentales (muy relacionada con la idiosincrasia propia de sus impulsores), la elaboración de estrategias para su estudio pasa invariablemente por un conocimiento lo más exhaustivo posible de sus herramientas de descripción y proceso evolutivo.

\section{Diseño de estrategias para la caracterización e investigación de las fuentes documentales}

Conscientes de la necesidad de abordar a largo plazo el estudio del fondo documental de estas instituciones (tanto nacionales como extrajeras), el CAS-IAPH ha trabajado sobre el diseño de estrategias de investigación desde la base de tres pilares fundamentales:

- Desarrollar proyectos propios de investigación.

- Fomentar programas de colaboración con otras instituciones de investigación.

- Impulsar la realización de jornadas técnicas de archivo para determinar las series de interés que, para el conocimiento del 
patrimonio arqueológico subacuático, se custodian en diferentes archivos nacionales y extranjeros.

Si bien esta última línea de acción está pendiente de desarrollo, en el campo de la colaboración institucional se viene trabajando desde el año 2000. El primer paso fue realizar un inventario de instituciones y grupos de investigación interesados en esta temática u otros afines. Lamentablemente, la limitada presencia de la arqueología subacuática en el ámbito académico universitario y la inexistencia de grupos de estudio en este terreno han impedido hasta el momento la firma de convenios concretos. Sin embargo, esto ayudó al CAS-IAPH a definir una línea de acción paralela encaminada a fomentar, desde el programa formativo del IAPH, la realización de cursos de iniciación y perfeccionamiento para la capacitación de arqueólogos en este campo patrimonial. Esta línea, iniciada en el año 2004, ha sido desde entonces fuertemente demandada, comenzando ahora a dar sus frutos. Como incentivo para el fomento de la investigación, se han convocado además varias becas de especialización, dedicadas, entre otros campos, al análisis y estudio de la documentación relativa a estos bienes culturales.

La labor directa de investigación realizada por el CAS-IAPH desde su creación ha sido amplia y productiva. Una de las primeras labores efectuadas en este proyecto, hace ahora diez años, fue la de localizar y contrastar la información histórica publicada hasta el momento sobre naufragios. En ese sentido, fueron de gran utilidad las referencias recogidas, además de en diversas publicaciones históricas (CHAUNU, 1983; GARCIAA-BAQUERO GONZÁLEZ, 1988; SERRANO MANGAS, 1991; entre otros), en un informe sobre naufragios en el Golfo de Cádiz (LAKEY, 1987)' realizado en el marco del proyecto Arqueología Submarina: Prospección y Valorización del Patrimonio Cultural Sumergido en el Golfo de Cádiz, una acción de cooperación bilateral entre España y Estados Unidos², promovida desde el Ministerio de Cultura de España, y cuya finalidad era localizar y estudiar naufragios en el área de la Bahía de Cádiz y la desembocadura del Guadalquivir, sin duda dos de las zonas de mayor concentración de naufragios a nivel mundial.

El informe recoge 377 referencias de naufragios listadas en función de criterios cronológicos y localización geográfica. Cada una de ellas va acompañada de su fuente de información, ya sea bibliográfica o de archivo, siendo el fondo del Archivo General de Indias el más utilizado. Sirvió de base para el desarrollo inicial de nuestras investigaciones, ayudando a definir tanto las estrategias de investigación a seguir como la necesidad de normalizar la información generada de cara a su almacenamiento y consulta.

Para abordar una línea de investigación tan compleja como la de caracterizar la documentación custodiada en los archivos de un elevado número de instituciones públicas y privadas generadoras de información de interés para nuestros fines, fue preciso diseñar un plan de acción plurianual que, en paralelo, permi- tiese, desde el primer momento, ir levantando y sistematizando la información relativa a los naufragios y siniestros marítimos que se encontrasen. Si bien los datos relativos al hundimiento de embarcaciones ayudan a referenciar y caracterizar posibles yacimientos arqueológicos por descubrir, los siniestros nos informan sobre zonas de riesgo para la navegación, referencias que nos parecieron de gran utilidad para, a medio plazo, abordar un estudio específico sobre ello y determinar zonas en las que, por su peligrosidad, puedan concentrase naufragios de todas las épocas. Este campo ha comenzado a dar sus frutos, sirviendo de apoyo para definir las Zonas de Servidumbre Arqueológica que recientemente ha declarado la Consejería de Cultura de la Junta de Andalucia para la protección de los posibles yacimientos que en ellas se localicen (ORDEN de 20 de abril de 2009).

La similitud en cuanto a funciones desempeñadas por las diferentes instituciones que generaron la documentación que dio origen a muchos de estos archivos (militar, notarial, gobierno y control municipal, etc.), y su homogéneo reparto por gran parte del territorio andaluz permitían diseñar una estrategia de trabajo para su estudio siguiendo criterios espaciales. En este sentido se decidió, en función a criterios de proximidad al centro de trabajo y de volumen e importancia patrimonial, abordar el análisis y caracterización del fondo documental de archivos emplazados en el entorno de la Bahía de Cádiz y el curso bajo del Guadalquivir, dos de las zonas en las que, como ya se ha apuntado, se localiza una de las mayores concentraciones de naufragios del mundo 3 .

\section{Diseño de herramientas para la gestión de la información y su normalización terminológica}

Desde un principio se vio la necesidad de disponer de un sistema informático para gestionar el elevado volumen de información que se estaba generando. Con este fin se creó Docusub, una aplicación informática básica, de gran agilidad, compatible con los sistemas de gestión espacial, en previsión de un futuro desarrollo de la misma.

Su estructura quedó articulada en siete grupos fundamentales de datos: identificación, cronologia, datos técnicos de construc-

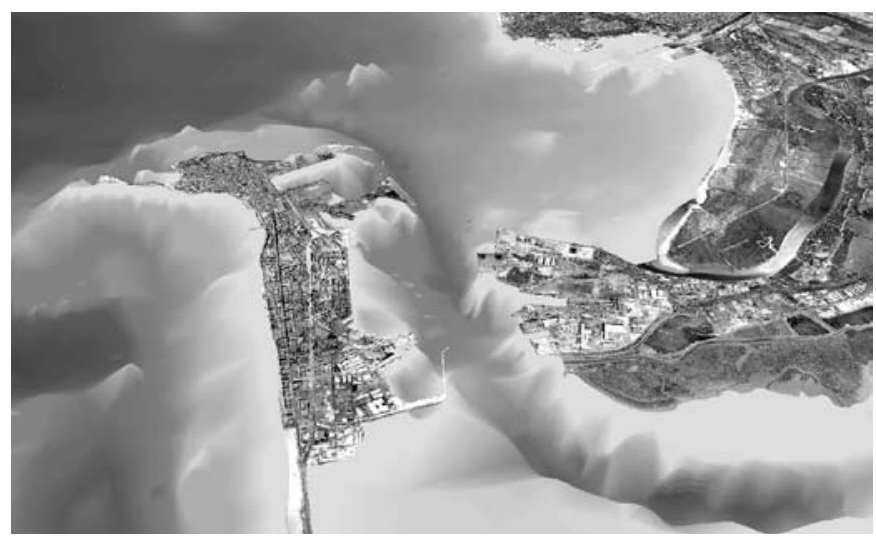

2. Imagen 3D de la Bahía de Cádiz elaborada desde SIGNauta. Fuente: CAS-IAPH 
ción, causas del accidente, datos sobre el rescate, información adicional y fuentes de información. Para garantizar la recuperación de la información se normalizaron todos los campos, salvo aquéllos de texto libre, como los que hacen referencia a las fuentes documentales de las que se extrae la referencia. La aplicación ha demostrado ser sumamente operativa. Además de tener una gran capacidad de recuperación de información por utilizar distintas fórmulas de búsqueda (nominales, cronológicas, territoriales, etc.), permite la elaboración de estadísticas mediante operadores booleanos.

La primera documentación volcada al sistema fue la procedente del informe sobre naufragios en el Golfo de Cádiz elaborado en el marco del proyecto Arqueología Submarina: Prospección y Valorización del Patrimonio Cultural Sumergido en el Golfo de Cádiz (LAKEY, 1987). En total aportó 377 registros. Con el paso del tiempo esta herramienta ha continuado alimentándose con información levantada en desarrollo de nuestra propia labor de investigación documental, hasta alcanzar en la actualidad las
1.007 referencias para aguas andaluzas, de las cuales 904 se localizan en el Golfo de Cádiz.

Docusub ha evolucionado con el tiempo. A partir de 2004 se decidió analizar la posibilidad de volcar la información a una herramienta SIG, aprovechando la agilidad y versatilidad que este tipo de sistemas ofrece. Así nació el Sistema de Información para la Gestión de la Información del Patrimonio Arqueológico Subacuático (SIGNauta), mucho más ambicioso y potente en cuanto al manejo de información y posibilidades de investigación y gestión (ALONSO VILLALOBOS et ál., 2007).

SIGNauta se ha organizado en seis módulos o subsistemas de temática diferente: Docusub, Yacsub, Siniestros, Ordenamiento, Obra Pública y Medio Físico.

- Docusub está alimentada, como ya hemos apuntado, de referencias documentales sobre naufragios, generalmente imprecisas en cuanto a la localización, salvo excepciones.

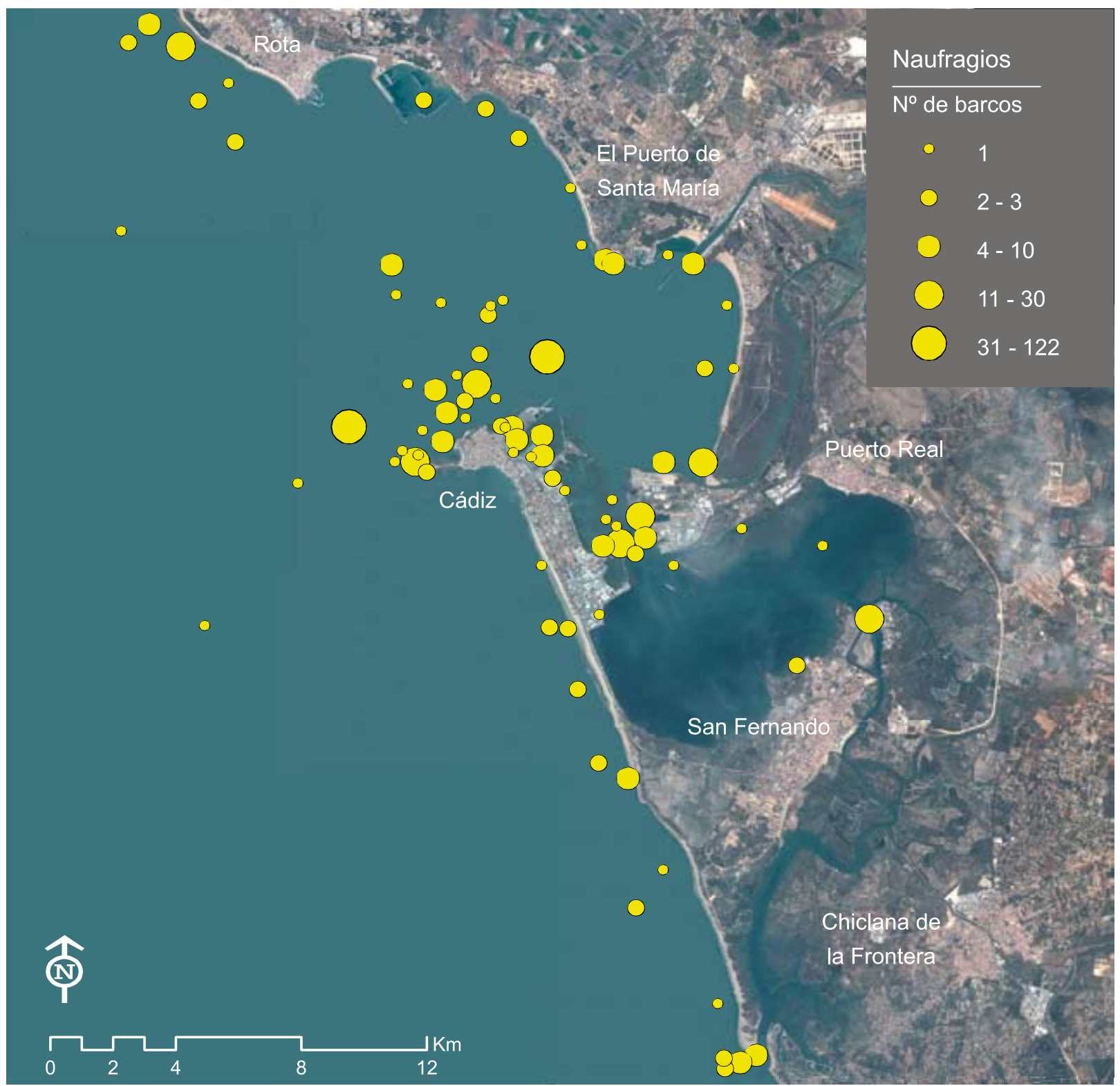


- Yacsub, que almacena noticias facilitadas por colaboradores que conocen la existencia de restos en zonas concretas y que, dependiendo de sus medios, aportan una localización aproximada de los mismos.

- Siniestros recoge información sobre accidentes ocurridos en el mar que no dieron lugar a un pecio, bien porque se rescataron los restos, bien porque se reflotó la embarcación.

- Ordenamiento contiene datos de tipo jurídico administrativo como líneas de base recta, espacios naturales protegidos, zonas militares, áreas portuarias, dominio público maritimo-terrestre, caladeros de pesca, etc.

- Obra pública, con referencia a obras civiles ejecutadas en el medio litoral relacionadas con el tráfico marítimo y portuario (dragados, construcción de diques y muelles, etc.), con aplicaciones energéticas (instalación de molinos eólicos en el mar) o de comunicación (tendido de cables submarinos), con la pesca (instalación de arrecifes artificiales), o con el turismo (regeneración de playas).

- Medio físico recopila información acerca del entorno ambiental en el que se encuentra el patrimonio y que afecta a su gestión (profundidad, naturaleza del fondo, salinidad, oleaje, etc.). Los datos que incluye son diacrónicos, por lo que pueden proceder, tanto de moderna instrumentación oceanográfica (datos geofísicos de ecosondas, sonar de barrido lateral, magnetómetro, etc.), como de antiguas cartas náuticas.

SIGNauta es una herramienta creada especificamente para la gestión del patrimonio arqueológico subacuático. Gracias a la correcta alimentación del subsistema de medio físico (principalmente con datos geofísicos, levantamientos batimétricos recientes y cartografía histórica digitalizada) es posible determinar, además de las zonas de riesgo para la navegación, cambios significativos en la morfología litoral (características litológicas del fondo, zonas colmatadas, modificaciones de la línea de costa, presencia de bancos de arena móviles, etc.). Si se tiene en cuenta que, debido a los cambios en la línea de costa, restos de barcos naufragados pueden encontrarse en la actualidad sepultados bajo playas emergidas, o estructuras bajo el mar por el retroceso costero, esta funcionalidad resulta de gran interés para definir riesgos y líneas de inves-

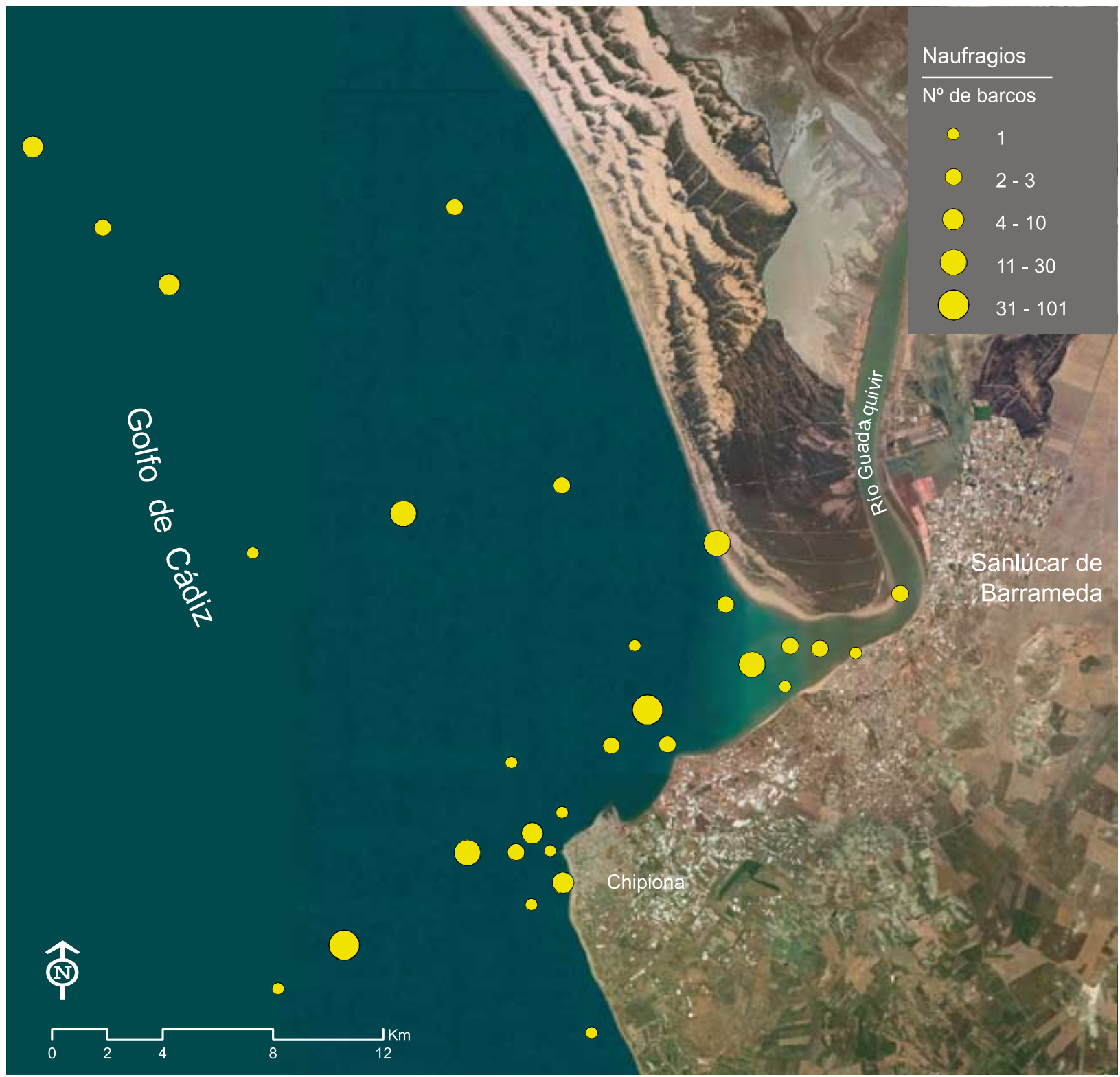

4. Naufragios en el área de la desembocadura del Guadalquivir (siglos XV-XIX). Fuente: CAS-IAPH 
tigación en relación con el patrimonio y su entorno. Igualmente, para prevenir el posible impacto de las obras públicas sobre los bienes culturales sumergidos, la herramienta permite comparar la situación batimétrica previa a la obra con la existente hace, al menos, tres siglos, gracias a la información de la cartografía histórica. En este sentido es de gran utilidad el uso de cálculos diferenciales en 3D para definir zonas de erosión y sedimentación (imagen 2).

Actualmente el Sistema está activo para el área de la Bahía de Cádiz (imagen 3) y la desembocadura del Río Guadalquivir (imagen 4), espacios sobre los que, como ya hemos apuntado, se han centrado los esfuerzos del proyecto de documentación por tratarse de dos zonas con un elevado número de naufragios constatados, tanto a través de las fuentes arqueológicas como de las documentales (ALONSO VILLALOBOS et ál., 2007: 29).

\section{Desarrollo de proyectos de investigación sobre las fuentes documentales}

Hasta el presente, el CAS-IAPH ha trabajado en las siguientes líneas de investigación:

\section{La tipificación de las fuentes documentales}

La experiencia adquirida en estos años de trabajo, en los que se ha tenido acceso a una amplia tipología de archivos, ha confirmado la existencia de muchas series documentales con información sobre naufragios históricos.

Han sido total o parcialmente analizados los fondos documentales de los siguientes archivos:

\section{- Archivos de la administración local}

Por su proximidad a la zona en la que se decidió focalizar los esfuerzos de este proyecto, se han analizado los fondos documentales de los Archivos Históricos Municipales de Cádiz, San Fernando, Puerto Real, Sanlúcar de Barrameda y Sevilla. Todos ellos guardan series documentales de gran interés. Entre ellas destacamos las denominadas Actas Capitulares, de las que se puede extraer información acerca de naufragios, obras de ingeniería portuaria, cegamiento de canales de navegación, zonas de fondeo, etc.

- Archivos de titularidad estatal y gestión autonómica

Entre el conjunto del fondo documental custodiado por los Archivos Históricos Provinciales destaca la serie documental de los Protocolos notariales. En ellos se recoge información perteneciente al ámbito de la fe pública, por lo que, de manera indirecta, hacen referencia al hundimiento de embarcaciones al tratar temas relacionados con reclamaciones de seguros, formación de compañias marítimas, testamentos de náufragos, etc. Debido a la importancia que a lo largo de los siglos tuvo la ciudad de Cádiz a nivel comercial, no sólo en relación con el nuevo continente, sino también con paises europeos, destaca el fondo del Archivo Histórico Provincial de Cádiz.

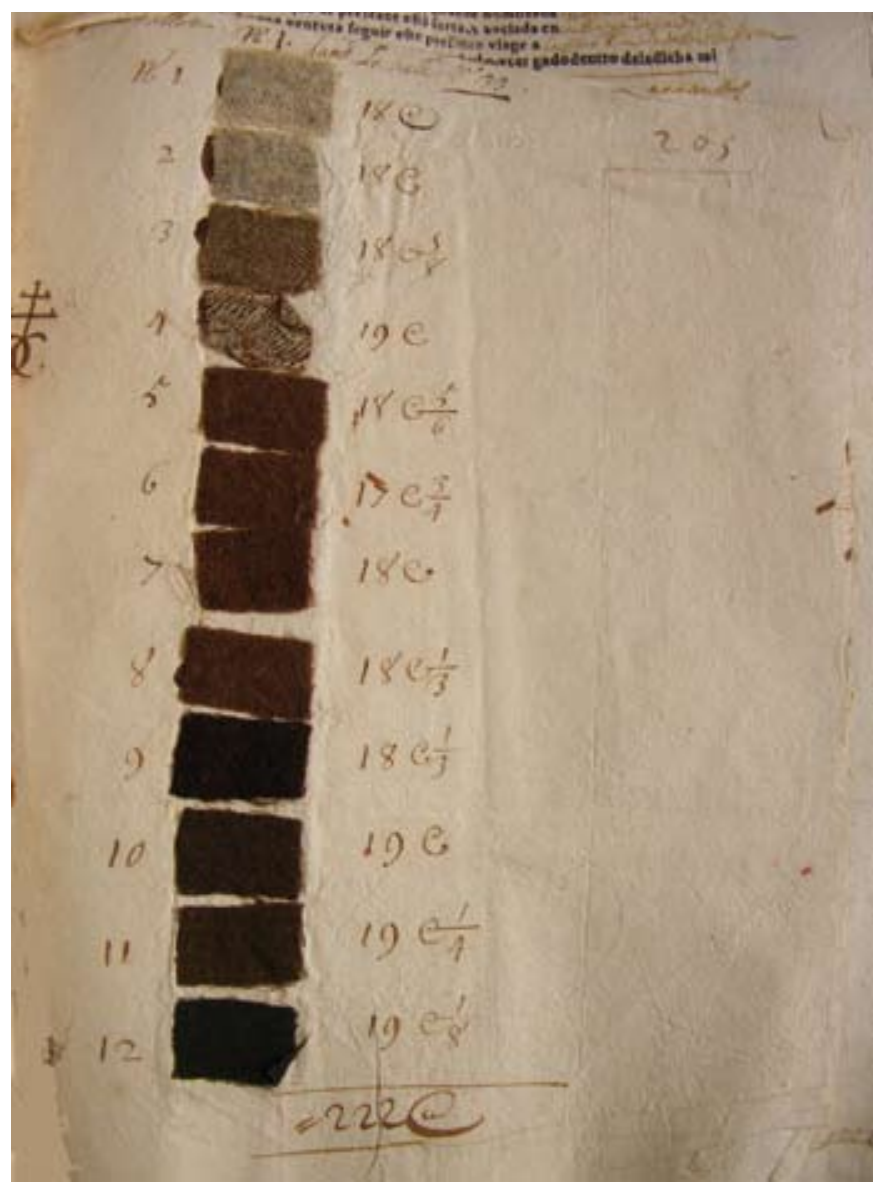

5. Memorial de reclamación de la carga del navío Nuestra Señora de la Concepción y San Miguel, naufragado en 1660, con muestras de paños. Foto: A. Valiente, CASIAPH. Fuente: Archivo Histórico de la Cámara de Comercio de Sevilla, Leg. 507

En el ámbito de la fe pública se encuentran los denominados protocolos notariales de las Escribanías de Marina, correspondientes a los asuntos del personal perteneciente al fuero militar de la Marina (SANZ TRELLES, 2006: 9). Sondeos de control efectuados para evaluar la importancia de su contenido, siguiendo criterios cronológicos, han servido para detectar la presencia de tipologías documentales de gran interés, como por ejemplo las cartas de pago y abandono, cuyo contenido hace referencia a la actividad crediticia del riesgo maritimo. El estudio de este tipo de documentos disperso por la serie ayudará sin duda en un futuro próximo a incrementar el número de referencias sobre nuevos naufragios.

- Archivos de titularidad estatal

El Archivo General de Indias es sin duda el archivo de titularidad estatal que custodia la documentación que ha permitido conocer hasta el momento un mayor número de referencias de naufragios. Explotado sistemáticamente desde hace años por historiadores $y_{1}$ en no pocos casos, por investigadores contratados por cazatesoros, alberga entre sus fondos las series documentales emanadas de la gestión de la Casa de Contratación en relación con el control del comercio con las colonias españolas de las Indias occidentales. Fue creado en 1785 por deseo expreso del monarca Carlos III para agrupar toda la documentación histórica existente sobre la América Virreinal hasta ese momento, dispersa entre Simancas, Cádiz y Sevilla. Así sus más de 43.000 legajos suponen una de las princi- 


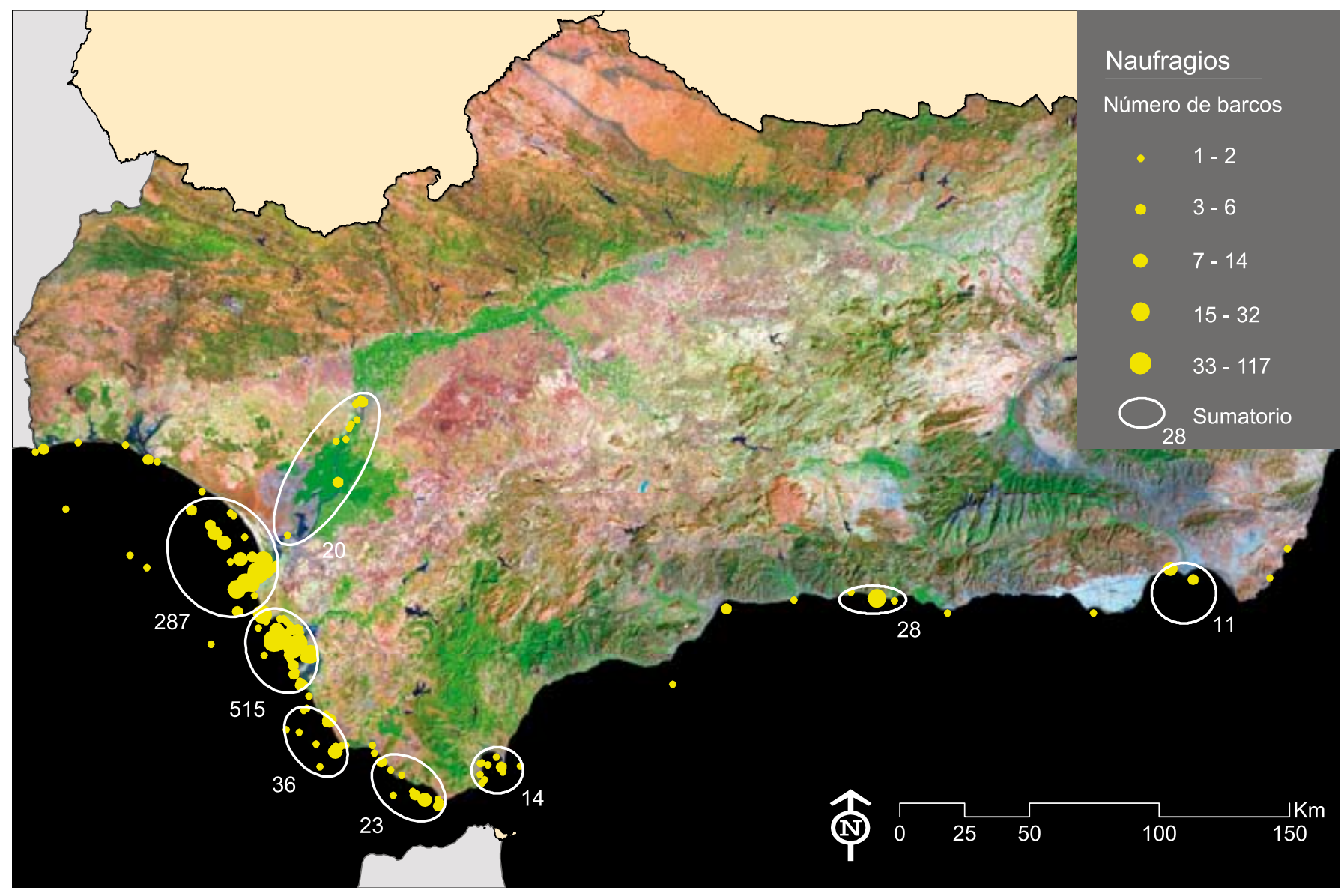

6. Naufragios en Andalucía (siglos XV-XIX). Fuente: CAS-IAPH

pales fuentes de información sobre el comercio transoceánico en la Edad Moderna y los naufragios derivados del mismo.

En su seno, la principal fuente de información la constituye la documentación fruto de la actividad de la Casa de la Contratación de Sevilla, agrupada mayoritariamente en la serie denominada Contratación. Realmente, esta sección o división intelectual y física de fondos documentales responde al archivo de la Casa, custodiando toda la documentación generada desde su creación por los Reyes Católicos en 1503 hasta su desaparición. Las funciones atribuidas a este órgano se fueron ampliando con el paso del tiempo, encomendándosele, entre otros asuntos, la realización de instrucciones para los navegantes y naves; realizar registros de las embarcaciones; la vigilancia del régimen de asientos, etc.

De entre todas sus funciones, las más importantes para nosotros, por su carácter intrínseco y el volumen de noticias sobre siniestros marítimos y naufragios, quizás sea la jurídica, dado que los pleitos generados aportan una información muy detallada. Otras muchas series y secciones documentales importantes son, por ejemplo, la serie segunda (Papeles de Carga) y la décimo tercera (Registros de Navios), en las que se recogen datos acerca de la carga, los viajes de cada año, el nombre del maestre, de capitán o dueño de la nao, etc.

Entre los archivos del Ministerio de Defensa, se ha efectuado una primera aproximación al contenido de las series documen- tales custodiadas en el Archivo del Instituto Hidrográfico de la Marina de Cádiz y el del Real Observatorio de la Armada de San Fernando. De este último destaca por su importancia la serie de cartografía náutica de los siglos XVIII al XIX de origen español, inglés y francés, serie que se completaba, para el siglo $X X$, con los levantamientos batimétricos del Instituto Hidrográfico. Se trata de una documentación de gran interés para el desarrollo de este tipo de proyecto por aportar información complementaria a la textual acerca de diversas temáticas. Además de posicionar datos directos de lugares de naufragios, informa sobre zonas de riesgo para la navegación y, lo que es igual de importante, nos deja ver, analizada diacrónicamente, las transformaciones que la línea de costa ha sufrido a lo largo de los últimos tres siglos.

Si bien con anterioridad al siglo XVIII este tipo de documentación sólo proporcionaba una información genérica y poco precisa sobre lugares y referencias de la costa, para ayudar a los pilotos a orientarse en la navegación de cabotaje, a partir de este momento, con el nacimiento de la navegación científica en la época de la llustración, las cartas náuticas se convierten en instrumentos cada vez más fiables sobre los que los marinos trazaban los rumbos en las singladuras.

Emanados de las competencias de las autoridades portuarias sobre el control y mejora de los puertos, los archivos de las Autoridades Portuarias de Cádiz y Sevilla almacenan una extensa información de carácter marítimo. La documentación custodiada ayuda tanto 
a determinar la evolución morfológica de los puertos, como el posible impacto que las obras de dragado y relleno hayan tenido sobre los yacimientos arqueológicos subacuáticos de la zona (MARTi SOLANO, 1994; MARTÍ SOLANO; GALLARDO ABÁRZUZA, 1998).

- Archivos de titularidad privada

Los archivos de titularidad privada tienen un origen muy variado, pudiendo distinguirse, a efectos de su caracterización, entre los generados por la actividad de instituciones y los emanados de la acción de compañías comerciales.

Entre los primeros destaca el Archivo de la Cámara de Comercio de Sevilla, cuyo fondo histórico se compone de 600 legajos pertenecientes en origen a distintas instituciones tales como el Tribunal del Consulado de Cargadores a Indias, Tribunal del Comercio o Universidad de Corredores de Lonja, todas ellas radicadas en la ciudad de Sevilla, solapándose en algunos casos sus funciones pero no su cronología. La fuerte vinculación de estas instituciones al comercio americano asi como la funcionalidad de las mismas han llevado a que en dicho fondo documental, de la misma manera que en el caso del Archivo General de Indias, se encuentre información para el conocimiento y contextualización de naufragios históricos. Una vez más, los documentos de carácter judicial (pleitos) son los que aportan una información más detallada, hasta el punto de que encontramos casos en los que se acompañan incluso muestras de los productos transportados por la embarcación que naufragó (imagen 5).

Los partes de vigía constituyen una serie documental muy característica. En ella se recoge la información que facilitaba el vigía de la ciudad (de manera impresa al principio y manuscrita después) relativa a aspectos relacionados con el tráfico comercial marítimo, entre ellos los siniestros o accidentes, asi como información respecto al posible rescate si lo hubiese. Para el caso de Cádiz, esta serie, iniciada en 1794 por el vigía de la Torre de Tavira, fue localizada casi completa $^{4}$ en el que fuera el fondo de una biblioteca privada, comprada y abierta al público gracias a la acción social de Unicaja bajo el nombre de Biblioteca de Temas Gaditanos Juvencio Maeztu. Al igual que ésta, en el proceso de identificación de instituciones que pudieran custodiar documentación se han localizado otras bibliotecas en cuyos fondos se custodiaba información fundamental para los fines de nuestro proyecto, como por ejemplo la Biblioteca del Casino de Cádiz, la Biblioteca del Almirante Lobo, gestionada por el Ayuntamiento de San Fernando, o la Garrison Library de Gibraltar.

En relación con los archivos generados por compañias privadas llama la atención el hecho de que la intensa actividad comercial marítima realizada por la metrópolis gaditana y toda su área de influencia durante la época moderna apenas dejara reflejo a nivel documental. Si bien muchos de ellos han desaparecido con el paso del tiempo, por destrucción o venta, se han podido localizar algunos de estos fondos. Entre ellos, los más importantes son: el Archivo de la Compañia Naviera Pinillo (Fundación Carmen Pinillos, Cádiz); el de la Compañía González de Peredo (Archivo Histórico Provincial de Cádiz); el Archivo Macpherson (Archivo de la Lloyds), repartido entre la propia com- pañia y la Unidad de Estudios Históricos del Vino de la Universidad de Cádiz, el Archivo de la Compañia Trasatlántica, repartido entre diversas instituciones (Biblioteca de Temas Gaditanos Juvencio Maeztu de Cádiz -UNICAJA-, Archivo del Dique del Astillero de Puerto Real -Cádiz-, Museo Marítimo de Barcelona y Archivo General de la Marina -Viso del Marqués, Ciudad Real-); el Archivo Lacave, custodiado en la unidad de Estudios Históricos del Vino de la Universidad de Cádiz, donde llegaron por donación de la propia familia.

\section{La investigación histórica}

Si bien las primeras labores en desarrollo de este proyecto han estado encaminadas a localizar y valorar el potencial de las fuentes de información relativas al patrimonio arqueológico subacuático, a lo largo de estos años se ha abordado, por motivos diversos, una línea de investigación para localizar e identificar naufragios.

Una de las primeras, coordinado desde el Área de intervención del CAS-IAPH, se desarrolló en el marco del Proyecto Trafalgar (MÁRQUEZ CARMONA, 2000). Se trata de un proyecto encaminado a localizar e identificar naufragios ocurridos a consecuencia del combate naval que tuvo lugar el 21 de octubre de 1805. La investigación efectuada en la fase de documentación del proyecto permitió contextualizar y determinar, en base a diferentes fuentes de información (prensa de la época, actas capitulares, cuadernos de bitácora, cartas náuticas, etc.), la zona aproximada de hundimiento de la casi totalidad de los quince navíos naufragados de la escuadra combinada hispano-francesa. Los restos de dos de ellos se han localizado en aguas próximas a San Fernando (posiblemente el navío francés Fougueux) y Cádiz (quizás el Bucentaure, buque insignia de la armada francesa) (GALLARDO ABÁRZUZA; MÁRQUEZ CARMONA, 2005; GARCÍA RIVERA et ál., 2009: 63-67).

Asimismo, hay que decir que el CAS ha realizado diversas actuaciones a petición de otras instituciones en el marco de ciertas operaciones relacionadas con el expolio del patrimonio arqueológico subacuático de Andalucía en particular y de España en general por parte de empresas profesionales de los conocidos popularmente como "cazatesoros".

En colaboración con los cuerpos de Seguridad del Estado, concretamente con el Grupo de Patrimonio Histórico de la Unidad Central Operativa de la Guardia Civil, en el marco de la Operación Géminis, se elaboró un informe valorando la documentación que, entre otros materiales, fue incautada a bordo de la embarcación Louisa, denunciada mientras presuntamente realizaba prospecciones subacuáticas ilegales de los fondos marinos del litoral de Cádiz. En total se analizó el contenido de unos 130 expedientes de tipología variada requisados en la embarcación, así como una cantidad aún mayor incautada en el domicilio de un colaborador. En casi la totalidad de esta documentación (reproducciones de documentos del Archivo General de Indias) se hace referencia al naufragio de embarcaciones que, cargadas con oro, plata o piedras preciosas, se perdieron a su regreso de las colonias americanas. Todas ellas fueron identificadas 


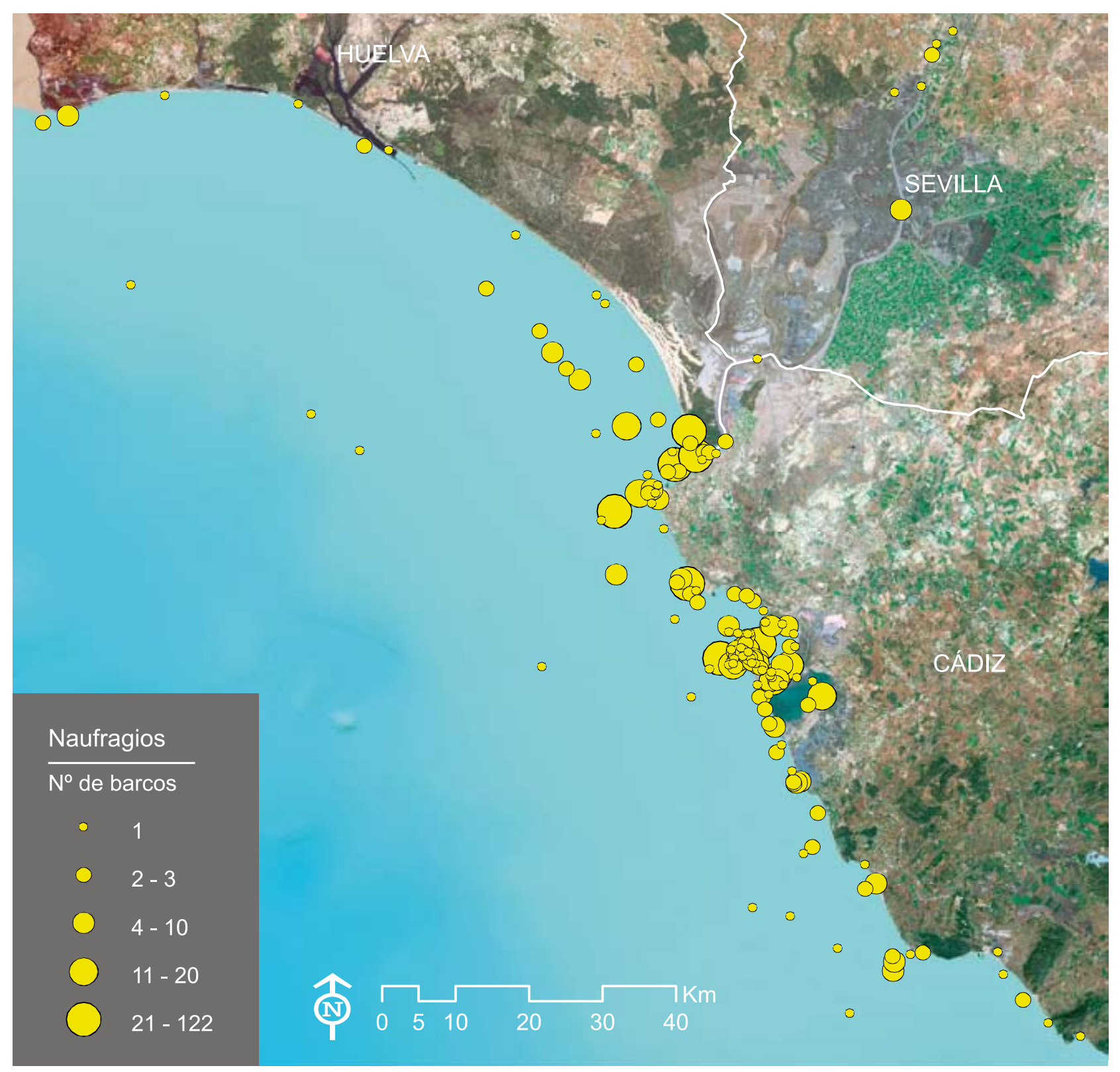

7. Naufragios en el Golfo de Cádiz (siglos XV-XIX). Fuente: CAS-IAPH

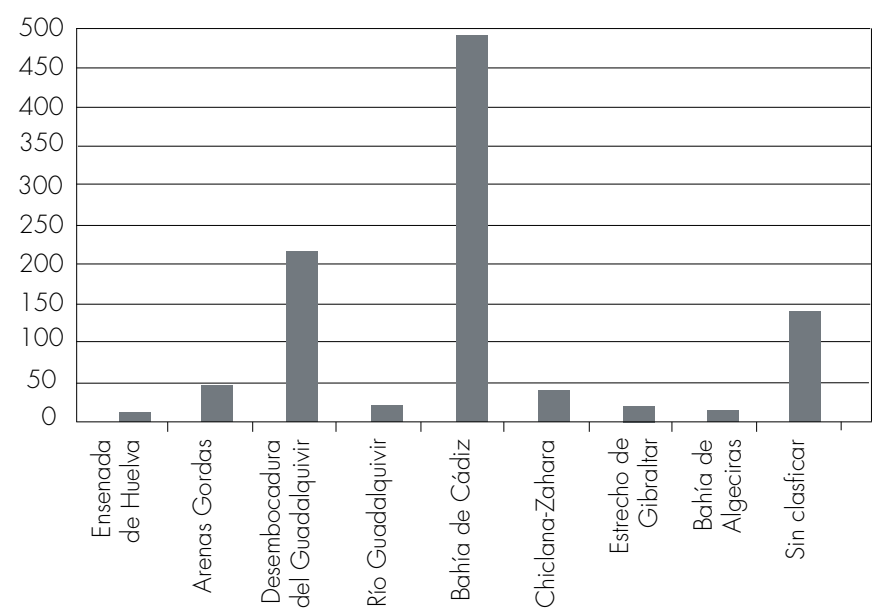

Gráfico 1. Naufragios documentados en el Golfo de Cádiz separados por áreas (siglos XV-XIX).

Fuente: CAS-IAPH

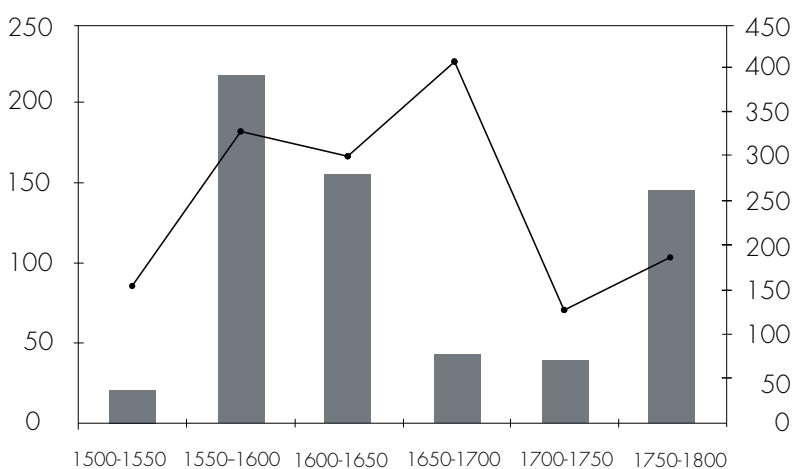

1500-1550 1550-1600 1600-1650 $\quad 1650-1700 \quad 1700-1750 \quad 1750-1800$

Número de naufragios Media de tonelaje

Gráfico 2. Tonelaje de embarcaciones perdidas documentadas en la desembocadura del Guadalquivir (1500-1800).

Fuente: CAS-IAPH 


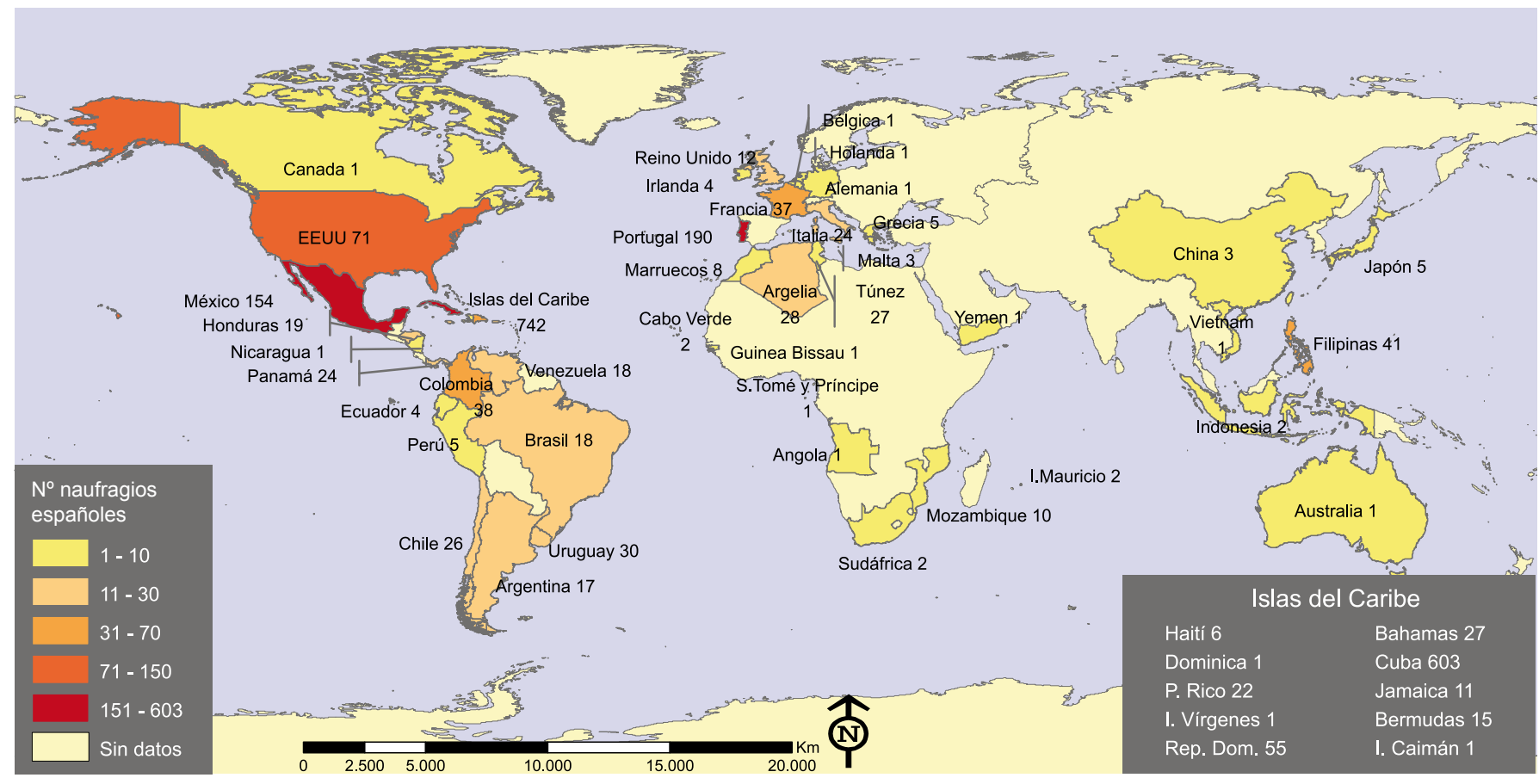

8. Naufragios españoles repartidos por el mundo (siglos XV-XIX). Fuente: CAS-IAPH

dado que sus nombres figuraban en la Base de Datos del CAS-IAPH, pudiéndose comprobar que las zonas de naufragio coincidian con espacios donde habian realizado prospecciones geofísicas.

En el año 2007, a petición en esta ocasión del Ministerio de Cultura, se investigó sobre la carga que la fragata española Nuestra Señora de las Mercedes transportaba el 14 de octubre de 1804 cuando fue hundida durante un ataque inglés (Combate de Cabo de Santa María) frente al litoral de Portugal, presumiblemente el pecio del que la empresa Odyssey podria haber extraido un cargamento de cerca de 500.000 monedas de oro y plata según los medios de comunicación internacionales.

Siguiendo con Odyssey, en ese mismo año el Ministerio de Cultura solicitó al CAS-IAPH su colaboración para ampliar el estudio que realizaba sobre el naufragio de la urca Merchant Royal. Al parecer, los restos de una embarcación así denominada habían sido localizados al suroeste de Inglaterra por la compañía de cazatesoros Odyssey. Los trabajos efectuados por técnicos del Centro en diferentes archivos (entre ellos el Archivo General de Simancas, Archivo Histórico Provincial de Servilla ${ }^{5}$ y Archivo General de Indias) permitieron recomponer la rocambolesca historia de este último viaje, antes de que el barco naufragara el 23 de septiembre de 1641 transportando hacia Flandes una valiosa carga de monedas de oro para hacer frente al pago de las tropas españolas alli destacadas.

\section{PRESENTE Y FUTURO DE LA INVESTIGACIÓN}

Siendo conscientes de que aún falta mucho camino por recorrer, podemos afirmar que los resultados obtenidos hasta el momento son bastante positivos, habiéndose alcanzado objetivos más que razonables, tanto a nivel cualitativo como cuantitativo.
Además de los 1.007 registros de naufragios (imagen 6) ocurridos en aguas andaluzas (904 en el Golfo de Cádiz -véase imagen7 y gráfico 1), se han localizado referencias a unos 1.500 pecios de pabellón español perdidos en aguas de otros países (imagen 8), todos ellos en un marco cronológico comprendido entre finales del siglo XV y final del XIX (sólo 18 pertenecen al siglo XX, pues, hasta el momento, no se han investigado las fuentes documentales recientes).

Aunque el volumen de información todavia es parcial, el análisis comparativo de los datos obtenidos permite efectuar estudios concretos que, sin duda, vendrán a arrojar luz sobre otros campos de investigación. Así, por ejemplo, en los resultados que se obtienen de cruzar datos del número de naufragios y tonelaje de las embarcaciones en Docusub, se observa claramente cómo, a lo largo de la Edad Moderna, tanto la media de tonelaje como el número de naufragios experimentan una tendencia similar, dinámica que se rompe en el intervalo comprendido entre 1650-1700 (gráfico 2). Para el resto del periodo existe un paralelismo entre el número de naufragios y la media de tonelaje de las embarcaciones, debido a que el aumento de éste no buscaba, fundamentalmente, aprovechar el espacio de carga de las naves, sino aumentar su capacidad de combate dada la gran cantidad de conflictos navales abiertos entre 1550-1600 (Combate de la Armada Invencible en el Canal de la Mancha, 1588; ataque de Drake a la Bahía de Cádiz, 1587; ataque Anglo-Holandés a Cádiz, 1596, etc.).

Entre 1650-1700 se observa una clara descompensación entre naufragios y tonelaje, debido, muy posiblemente, a la crisis en la que se encuentra la monarquia durante el reinado de Carlos II y a la situación insostenible en la que está el Estado, necesitado de recursos económicos para continuar su actividad. Esto se traduce en un sobredimensionamiento de las embarcaciones que realizaban la carrera de indias para rentabilizar al máximo las expediciones. El 
desarrollo de futuros estudios en esta línea permitirá, posiblemente, caracterizar cronológicamente determinados tipos de navíos en función de su tamaño, lo que puede ser de gran utilidad en el proceso de investigación arqueológica de los pecios.

El análisis de la cartografía histórica ha mostrado ser un campo de gran interés para el diseño de estrategias de investigación y gestión. Las transformaciones de la línea de costa o del curso de los ríos navegables (como en el caso del Guadalquivir, en proceso de estudio en la actualidad) han venido a alterar la posición originaria de algunos yacimientos arqueológicos, dejando bajo agua antiguas estructuras costeras y sepultados bajo la tierra restos de embarcaciones (véase al efecto ALONSO VILLALLOBOS; MENANTEAU, 2009), generando una casuística de tutela que, aunque menos frecuente, es necesario tener en consideración.

La información levantada procede del análisis de fuentes documentales primarias pertenecientes a un marco cronológico concreto (siglos XV-XIX). Sin embargo, las conclusiones que se pueden obtener de cruzar, entre otras, información acerca de zonas históricas recurrentes de siniestros maritimos, lugares de riesgo para la navegación en función a morfología del fondo, vientos, corrientes, etc., de coeficientes mareales (para la zona atlántica), calado de las embarcaciones, serán de gran ayuda para definir áreas en las que es probable la presencia de pecios de momentos anteriores para los que, desgraciadamente, no se han conservado fuentes escritas tan explícitas como las de Época Moderna.

Como ya se ha señalado, todo el trabajo realizado hasta la actualidad se ha centrado en el estudio de los archivos y fondos documentales del área del Golfo de Cádiz, especialmente la Bahía de Cádiz y el área de Guadalquivir. La extensión de este estudio al resto del territorio andaluz vendrá a multiplicar considerablemente la información sobre el patrimonio cultural sumergido de esta comunidad, ayudando a perfilar estrategias con mayor precisión.

\section{Notas}

${ }^{1}$ Este trabajo, cuyo informe final citamos, fue dirigido por Denise C. Lakey y realizado por un equipo de investigación hispano-norteamericano.

${ }^{2}$ Esta acción fue promovida desde el Comité Conjunto Hispano-Norteamericano para la Cooperación Cultural y Educativa, estando dirigida por Manuel Martín Bueno, de la parte española, y por George F. Bass, de la norteamericana.

${ }^{3}$ Por el Golfo de Cádiz han navegado embarcaciones fenicias, griegas, púnicas, romanas, árabes, normandas, etc. A partir del siglo XV, bajo el control de la Corona de Castilla y Aragón, fue punto de partida y arribada en la ruta hacia el nuevo continente. Muchas de ellas nunca llegaron a su destino, conservándose sus restos bajos estas aguas. Cualquier información que permita extraer conclusiones acerca de las zonas de naufragios, las rutas históricas de navegación, los puntos de aguada y fondeo, los bajos o lugares peligrosos por vientos, corrientes, etc., puede ser de gran interés para la tutela de este ingente patrimonio olvidado del que, lamentablemente, sólo en una mínima parte, conservamos fuentes escritas.

${ }^{4}$ Los números correspondientes a los años 1851-1874 se localizaron en la Biblioteca Nacional.

${ }^{5}$ Carlos Álvarez Nogal. Profesor de Historia de la Economía. Universidad Carlos III de Madrid.

\section{Bibliografía}

ALONSO VILLALOBOS, C; BENITEZ LÓPEZ, D.; MÁROUEZ CARMONA, L.; VALIENTE ROMERO, A.; RAMOS MIGUÉLEZ, S.; MARTíNEZ DEL POZO, J. A. (2007) SIGNauta: un sistema para la información y gestión del patrimonio arqueológico subacuático de Andalucía. PH: Boletín del Instituto Andaluz del Patrimonio Histórico, n 63 , 2007, pp. 26-41

ALONSO VILLALLOBOS, C.; MENANTEAU, L. (2009) Les ports antiques de la côte atlantique de l'Andalousie, du Bas-Guadalquivir au détroit de Gibraltar. Problématique et étude de cas (Baelo, Tarifa). En Les structures portuaires de l'Arc atlantique dans I'Antiquité: Bilan et perspectives de recherche. Journée d'études, Université de la Rochelle 24 janvier 2007 (en prensa)

ALZAGA GARCÍA, M.; MARTí SOLANO, J.; NAVARRO DOMÍNGUEZ, M.; RODRÍGUEZ MARISCAL, N. (1999) Documentación y análisis del riesgo antrópico del patrimonio arqueológico subacuático de Andalucía. PH: Boletín del Instituto Andaluz del Patrimonio Histórico, n² 26, 1999, pp. 122-129

BONO Y HUERTA, J. (1992) Conceptos fundamentales de Diplomática notarial. Historia, instituciones, documentos, n 19, 1992, pp. 73-88

CHAUNU, P. (1983) Sevilla y América: siglos XVI y XVII. Sevilla: Universidad, 1983 GALLARDO ABÁRZUZA, M.; MÁRQUEZ CARMONA, L. (2005) Los naufragios de la Batalla de Trafalgar. PH: Boletín del Instituto Andaluz del Patrimonio Histórico, n०55, 2005, pp. 86-92

GARCÍA-BAQUERO GONZÁLEZ, A. (1988) Cádiz y el Atlántico (1717-1778): el comercio colonial español bajo el monopolio gaditano. Cádiz: Diputación, 1988 GARCÍA RIVERA, C.; ZAMBRANO VALDIVIA, L. C. (2003) El Centro de Arqueología Subacuática de la Comunidad Autónoma andaluza y la conservación del material arqueológico. Monte Buciero, no 9, 2009, pp. 189-203

GARCÍA RIVERA, C.; ALZAGA GARCÍA, M. (2008) La Carta Arqueológica Subacuática de Andalucía como instrumento para la tutela de un patrimonio emergente. Mainake, n³0, 2008, pp. 129-143

GARCÍA RIVERA, C.; ZAMBRANO VALDIVIA, L. C.; ALONSO VILLALOBOS, C.; GALLARDO ABÁRZUZA, M.; PUEBLA RODRíGUEZ, J. (1999) Proyectos de tutela del Patrimonio subacuático realizados por el Centro de Arqueología Subacuática. PH: Boletín del Instituto Andaluz del Patrimonio Histórico, n² 26, 1999, pp. 130-137 GARCÍA RIVERA, C.; ALZAGA GARCÍA, M.; MARTí SOLANO, J.; RODRÍGUEZ MARISCAL, N. E. (2009) El Centro de Arqueología Subacuática de Andalucía. La protección del patrimonio arqueológico subacuático. Arqueología Náutica Mediterrànea (Monografias del CASC, 8). Girona: Museo d'Arqueología de Catalunya, 2009, pp. 54-67

LAKEY, D. C. (1987) Shipwrecks in the Gulf of Cadiz: A Catalog of historically documented wrecks from the fifteenth through the nineteenth centuries. Final Report, May, 1987

MÁROUEZ CARMONA, L. (2000) Trafalgar: investigación de las fuentes documentales. PH: Boletín del Instituto Andaluz del Patrimonio Histórico, n 32, 2000, pp. $163-174$

MARTí SOLANO, J.; GALLARDO ABÁRZUZA, M. (1998) Arqueologia y obras de dragado en la Bahía de Cádiz: evolución, desarrollo y perspectivas. En III Jornadas de Arqueología Subacuática. Valencia: Facultat de Geografía e Història, 1998, pp. 145-153 MARTí SOLANO, J. (1994) Los dragados de la Bahía de Cádiz. Métodos de control y análisis de materiales. En RAMALLO ASENSIO, S. (coord.) Aulas del Mar. Arqueología Subacuática I. Murcia: Universidad, 1994, pp. 117-132

ORDEN de 20 de abril de 2009, por la que se resuelve declarar como Zonas de Servidumbre arqueológica 42 espacios definidos en las aguas continentales e interiores de Andalucia, mar territorial y plataforma continental ribereña al territorio andaluz. Boletín Oficial de la Junta de Andalucia, n 101, 2009, pp. 59-73

SANZ TRELLES, A. (2006) Catálogo de la Escribanía de Marina de Cádiz (17781883). Sevilla: Consejeria de Cultura, 2006

SERRANO MANGAS, F. (1991) Naufragios y rescates en el tráfico indiano durante el siglo XVII. Madrid: Sociedad Estatal para el Quinto Centenario, 1991

VALIENTE ROMERO, A.; MÁROUEZ CARMONA, L. (2006) De Tolón a Trafalgar: las operaciones de la escuadra combinada a través de la Gaceta de Madrid. Trocadero, no 18, 2006, pp. 161-176 